\title{
How should I treat a coronary artery to pulmonary artery fistula at an acute stent thrombosis site?
}

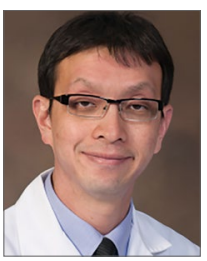

Arun Kannan ${ }^{1}$, MD; Justin Z. Lee ${ }^{1}$, MD; Layth Saleh², MD; Uday Kanakadandi², MD; Gianluca Rigatelli ${ }^{3}$ MD, PhD; Kwan S. Lee ${ }^{2 *}, \mathrm{MD}, \mathrm{FACC}$

\begin{abstract}
1. Department of Internal Medicine, University of Arizona, Tucson, AZ, USA; 2. Department of Cardiovascular Diseases, University of Arizona, Tucson, AZ, USA; 3. Section of Adult Congenital Heart Interventions, Rovigo General Hospital, Rovigo, Italy
\end{abstract}

Invited experts: Jaroslaw D. Kasprzak4, MD, FESC, FACC; Igor F. Palacios ${ }^{5}$, MD

4. Department of Cardiology, Medical University of Lodz, Bieganski Hospital, Lodz, Poland; 5. Harvard Medical School and Department of Interventional Cardiology, Massachusetts General Hospital, Boston, MA, USA

The concluding section "How did I treat?" together with the complete references and the supplementary data are published online at: http://www.pcronline.com/eurointervention/126th_issue/216

\section{CASE SUMMARY}

BACKGROUND: A 58-year-old male with a history of intracranial haemorrhage presented with an acute inferior STEMI secondary to an acutely occluded RCA, treated with a $5.0 \mathrm{~mm}$ bare metal stent. Four months later, he presented with a recurrent acute inferior STEMI.

INVESTIGATION: Cardiac catheterisation revealed an ARC definite in-segment late stent thrombosis of the bare metal stent. The previously seen atrial branch from the proximal RCA was now visualised as a large RCA to pulmonary artery fistula.

DIAGNOSIS: The high flow fistula from RCA to pulmonary artery is thought to have caused coronary steal phenomenon, resulting in in-stent thrombosis.

MANAGEMENT: Embolisation of the fistula was carried out with helical and interlocking coils being deployed, and balloon angioplasty of the in-stent thrombosis was performed at high pressure. Occlusion of the fistula and return of flow was confirmed.

KEYWORDS: coronary fistula, in-stent thrombosis, pulmonary artery, right coronary artery

\section{PRESENTATION OF THE CASE}

A 58-year-old male with a history of intracranial haemorrhage from an intracerebral AV malformation, complicated by frontal lobe syndrome and seizures presented with an acute inferior ST-elevation myocardial infarction. Emergent cardiac catheterisation was performed, but he became increasingly agitated, violent and combative during the initial portion of the procedure, requiring emergent deep sedation, paralysis and endotracheal intubation with mechanical ventilation. Coronary angiography revealed a patent but ectatic left coronary system and an acutely occluded mid right coronary artery (RCA) with large thrombus burden (Figure 1). The proximal RCA gave rise to what appeared to be an atrial branch, which was not completely visualised distally during his acute care. Procedural anticoagulation was achieved with IV unfractionated heparin and abciximab. Aspiration thrombectomy was performed with an Xpress-Way ${ }^{\mathrm{TM}} \mathrm{RX}$ Extraction Catheter (Atrium Medical Corporation, Hudson, NH, USA). A ClearWay ${ }^{\mathrm{TM}}$ RX drug delivery balloon (Atrium Medical Corporation) was advanced into the lesion and intracoronary thrombolysis was performed with $4 \mathrm{mg}$ of t-PA and $10 \mathrm{mg}$ of abciximab delivered directly into the thrombus. The lesion was then stented with a $5.0 \times 28 \mathrm{~mm}$ MULTI-LINK ULTRA ${ }^{\mathrm{TM}}$ Coronary Stent System (Abbott Vascular, Santa Clara, CA, USA) (Figure 2). Intravascular ultrasound was performed pre and post device delivery. The proximal mean reference diameter was $5.7 \mathrm{~mm}$ and distal mean reference diameter was $3.7 \mathrm{~mm}$. Post intervention, the mean stented area was $15.8 \mathrm{~mm}^{2}$ and mean diameter was $4.6 \mathrm{~mm}$. Excellent stent apposition was noted (Figure 3).

*Corresponding author: Department of Cardiovascular Diseases, University of Arizona, 3950 S Country Club Road,

Suite 200, Tucson, AZ 85714,USA.E-mail: klee@shc.arizona.edu 


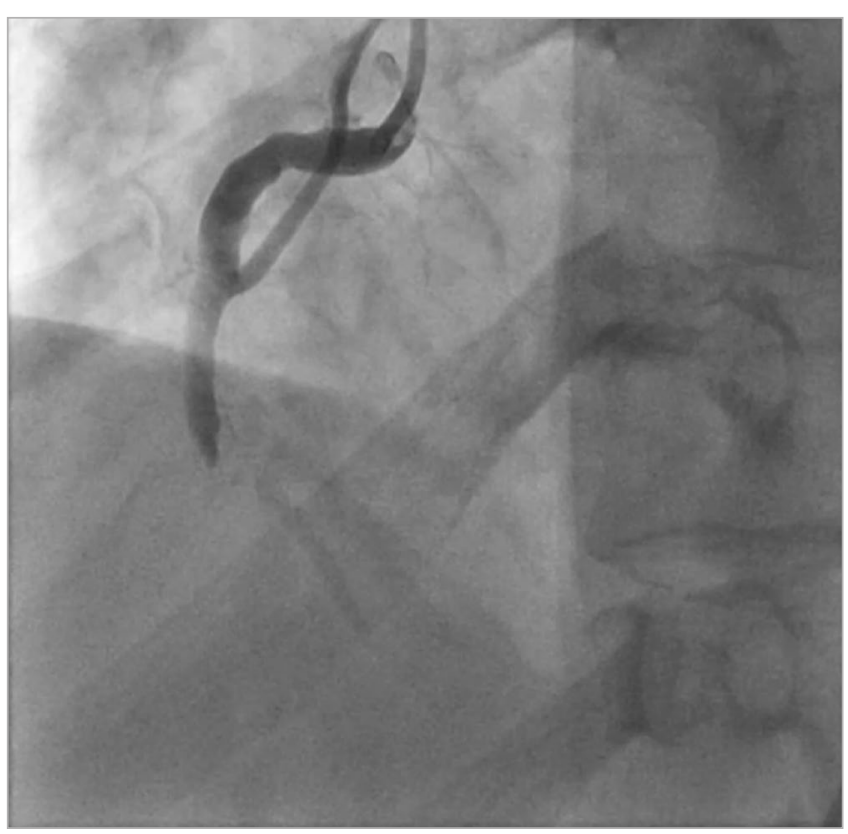

Figure 1. Coronary angiogram showing acute thrombotic occlusion of the mid right coronary artery. The atrial branch is seen in the proximal portion.
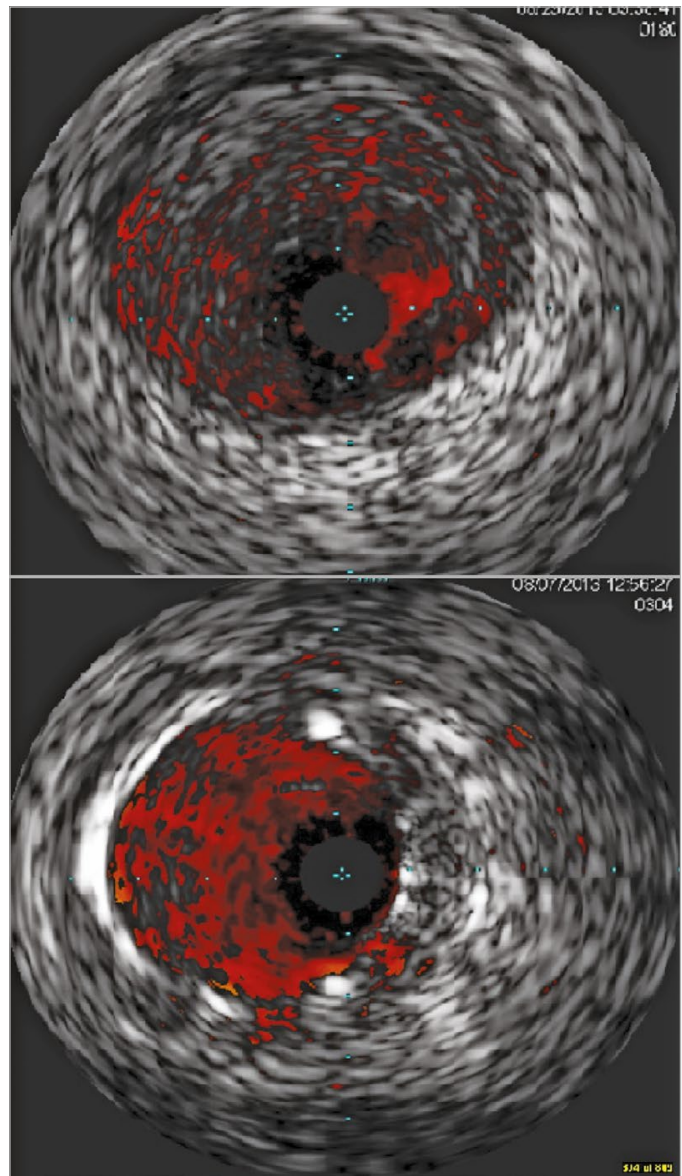

Figure 2. Intravascular ultrasound images pre intervention (top panel) and post intervention (bottom panel) showing good stent apposition and no procedural complications.

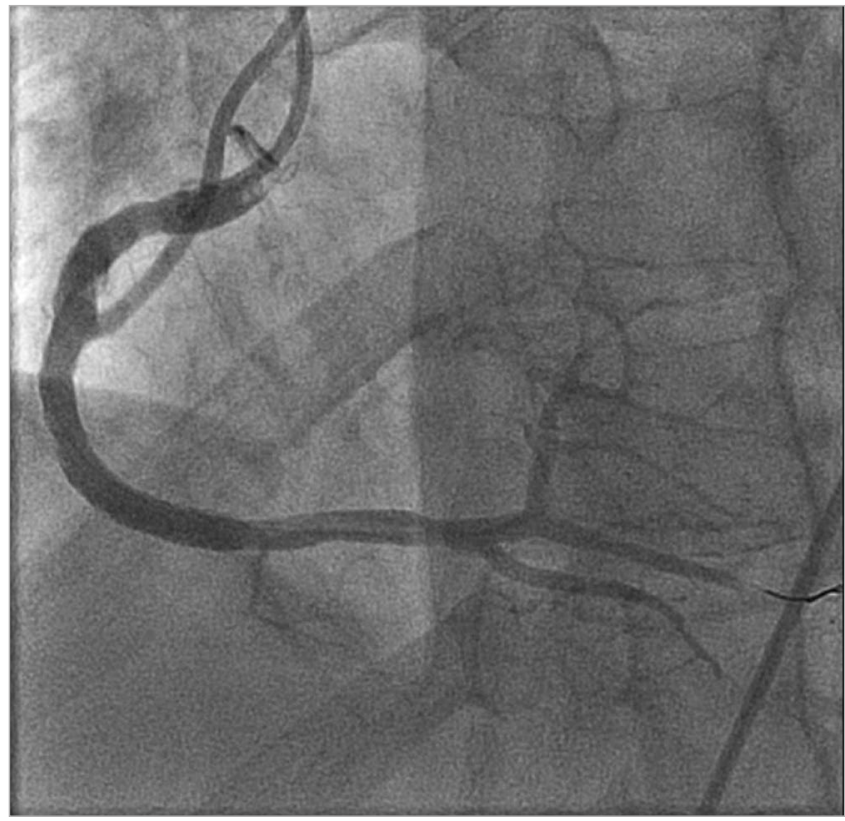

Figure 3. Coronary angiogram post intervention revealing a large dominant right coronary artery.

A bare metal stent was used due to the large vessel diameter, potential for further intracranial bleeding and possible future medication non-adherence. He made an excellent recovery from this event and was extubated the following day. A transthoracic echocardiogram showed mild inferior and inferoseptal hypokinesis with normal left ventricular ejection fraction at $60 \%$. He was discharged on aspirin and clopidogrel. One month later, he developed minor intracranial bleeding and clopidogrel was stopped with continuation of his aspirin. Two months later, he developed symptomatic bradycardia, with episodes of presyncope due to sick sinus syndrome, and underwent dual-chamber pacemaker implantation.

Four months after the original myocardial infarction, he presented with a recurrent acute inferior wall ST-elevation myocardial infarction. He was prophylactically sedated, paralysed and intubated on this occasion in anticipation of possible recurrent violent behaviour with conscious sedation. Emergent coronary angiography was performed, which showed an ARC-definite insegment late stent thrombosis of the recently placed $5.0 \times 28 \mathrm{~mm}$ bare metal stent. Also clearly seen on this occasion was that the previously incompletely visualised right atrial branch was actually a large RCA to right pulmonary artery (PA) fistula that was missed on the prior angiography. This high flow coronary fistula immediately proximal to the stent was thought to be causing coronary steal and contributing to stent thrombosis. How would you manage this patient, given the new findings and his history of intracranial bleeding? 


\section{How would I treat? THE INVITED EXPERT'S OPINION}

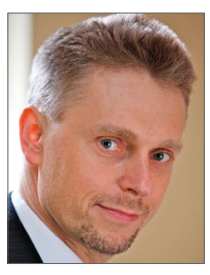

Jaroslaw D. Kasprzak ${ }^{4 *}$, MD, FESC, FACC

4. Department of Cardiology, Medical University of Lodz, Bieganski Hospital, Lodz, Poland

Coronary fistulas are relatively uncommon congenital connections of coronary arterial branches and cardiac chambers or large vessels. While large connections, resulting in generalised coronary artery dilatation and large, low resistance flow, have well defined haemodynamic consequences (steal phenomenon potentially leading to coronary ischaemia and volumetric shunt flow resulting in imbalance between systemic and coronary circulation), they are often diagnosed in childhood, usually representing a "paediatric" type of the disease (although adults with the conditions also exist). Much more commonly, moderate or small coronary fistulas are accidentally diagnosed at coronary angiography performed for standard indications and represent a much more questionable therapeutic target. However, the solid bulk of case reports supports intervention (usually percutaneous) in patients with haemodynamically significant flow across the fistula causing pulmonary hypertension or an otherwise significant shunt, or, alternatively, coronary flow steal causing myocardial ischaemia.

The clinical situation presented belongs to the second case scenario. The patient has had his (presumably) first coronary angiography in the setting of an acute inferior infarction, optimally treated with primary angioplasty and a well taken decision to use bare metal stenting with aspiration thrombectomy and IVUS-based optimisation of the acute procedure. Considering previous intracardiac bleeding and the size of the right coronary artery (unfortunately the left coronary artery is not shown but just described as dilated, with no information on the patient's body size, etc.) this was the right choice! However, at this point the patient will certainly be a candidate for antiplatelet drugs in the future so the continuum of care should include initiation of neurological/neurosurgical work-up as the bleeding risk, inherently high in patients with brain arteriovenous malformation (BAVM), becomes almost a $100 \%$ certainty.

The core of the analysed problem arose four months later (indeed after a minor intracranial bleeding, conversion from dual antiplatelet therapy [DAPT] to single antiplatelet therapy [SAPT]) when a subsequent infarction occurred, due to in-segment rather than in-stent thrombosis.

Why did this happen? There are many potential components of such a complicated clinical course. The initial procedure seemed optimal so that iatrogenic local issues are less likely. In my view, the critical aspect was the absence of DAPT in month four after STEMI. Here we return to the issue of the BAVM - there is no indication of how it was handled in the meantime. Of course, we do not need DAPT protection for a BMS stent, but we should protect a vulnerable patient, optimally for a year; this component was missing. We do not have any information on concomitant medical therapy, especially statins and RAA inhibitors and beta-adrenolytics, which help minimise the risk of subsequent coronary events. The most intriguing piece of the puzzle is the contribution (or lack thereof?) of flow abnormalities related to coexistent coronary artery-pulmonary artery fistula. Such a pity we cannot see the distal course/diameter and coronary-pulmonary connection on the Figures!

So, there are two questions to answer:

1. Should we occlude the fistula at all or leave it alone?

2. If justified, should the occlusion be performed $a d$ hoc or delayed as a separate procedure?

*Corresponding author: Department of Cardiology, Medical University of Lodz, Bieganski Hospital, Kniaziewicza 1/5, 91-347 Lodz, Poland. E-mail: kasprzak@ptkardio.pl 
Regarding the closure options, coronary fistulas may be closed by surgery (clearly not a good choice in the patient under discussion), by occluding the orifice of the feeding artery with a covered stent (significant thrombotic or restenotic risk is prohibitive given the history of the patient) or implanting an occlusive device more distally in the feeding artery (most commonly coils or small vascular plugs) - this could potentially be delivered after opening an infarct-related artery. However, the unpredictable and dynamic prothrombotic and proinflammatory milieu of acute coronary syndrome is, for me, a sufficient argument to postpone the fistula occlusion. This way we also win time for the second thought is the fistula a true therapeutic target in our patient? Or, in other words, would our decision put our patient at unnecessary risk of an avoidable recurrent event?

Myocardial ischaemia due to coronary steal has been documented in several case reports, including demonstration of abnormal myocardial perfusion scan, reversible after the occlusion of the fistula. However, the relationship of the fistula and acute infarction is disputable. Single case reports suggesting, but rarely proving, causality have been published, the most convincing of them reporting fistula thrombosis with backward propagation of the thrombus into the circumflex artery in the setting of a dilated left main coronary artery. Objective sizing of coronary fistulae is complex and not standardised. Proposed approaches include assessing angiographic features, calculation of Qp/Qs or proving myocardial ischaemia. In angiography, there is no approved quantification system; some authors have suggested considering as trivial/small those fistulas which result in little or no dilation of the proximal feeding coronary artery and are themselves no larger than twice the normal expected diameter of the proximal coronary artery. This seems to be the case in the patient under discussion (although the angiographic Figures are incomplete - we can only rely on the notion of high-flow fistula, without argumentation and with a controversial angiographic still frame). There is no visible underfilling of the right coronary artery distal to the origin of the fistula feeder. Very importantly, the patient is adult with no history of preceding angina (except for the first infarction with acute vessel thrombosis) or pulmonary hypertension (at least none of them is mentioned in the case description). Taking this all together, the haemodynamic significance of this presumably congenital fistula is probably mild or in the worst case uncertain, and the relationship to acute stent thrombosis is purely speculative. The contribution of decreased forward flow distal to the feeding branch as a pathomechanism of thrombosis is elusive and unproven. Contrarily, delaying the fistula procedure might allow performing typical tests for coronary ischaemia - gated SPECT or, even better, a PET study with myocardial flow quantification ${ }^{1-5}$.

Therefore, my suggested treatment in this case is:

1. To perform effective reperfusion of the acute in-segment thrombosis in a patient at high risk of bleeding which in itself is a clinical conundrum - probably again thrombectomy and bare metal stenting (or balloon angioplasty alone?).

2. The patient should undergo work-up for acetylsalicylic acid resistance and thrombophilia, especially if a new stent is implanted.

3. When the condition stabilises, neurological evaluation should be performed to pave the way for BAVM intervention, as the patient has an expected, lifelong, very high risk of bleeding/ high risk of atherothrombosis dilemma.

4. Multimodality imaging should be used to assess the significance of congenital coronary fistula objectively and guide the final decision. This may be a consecutive procedure, presumably with coil embolisation (but angiographic details additional to those given in the case report are needed). The risk of additional elective coronary catheterisation is, in my view, negligible and counterbalanced by better understanding of the pathophysiological background.

\section{Conflict of interest statement}

The author has no conflicts of interest to declare. 


\section{How would I treat? THE INVITED EXPERT'S OPINION}

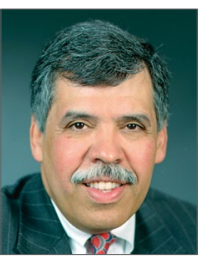

Igor F. Palacios ${ }^{5 *}$, MD
In this case presentation, Kannan et al report a 58-year-old man with a history of intracranial haemorrhage from an intracerebral AV malformation presenting with an inferior STEMI. He underwent successful PCI with implantation of a $5.0 \times 28 \mathrm{~mm}$ MULTILINK ULTRA Coronary (bare metal) Stent System with good immediate angiographic and intravascular ultrasound results. He developed a minor intracranial bleeding one month later. His clopidogrel was discontinued; he was continued on aspirin. Two months later he developed a presyncopal episode due to symptomatic bradycardia and sick sinus syndrome. A dual chamber permanent pacemaker was implanted. Four months later he developed a recurrent inferior STEMI. A large RCA to PA coronary AV fistula was identified in this study and I have been asked how to manage this coronary RCA fistula.

Coronary artery fistula is an unusual coronary anomaly ${ }^{6,7}$. Most coronary artery fistulas are congenital, but the incidence of acquired fistulas is increasing as a result of the incremental use of intravascular procedures and interventional techniques. The prevalence of coronary AV fistulas is about $0.1-0.8 \%$ based on coronary angiography or echocardiography studies. Most of them drain into the right atrium, right ventricle and pulmonary artery. A few of them drain into the left ventricle, the left atrium, or the coronary sinus $^{6-8}$. Large fistulas can induce congestive heart failure, angina, myocardial infarction, arrhythmia or pulmonary hypertension. Endocarditis, coronary artery rupture and sudden cardiac death have also been reported. Cardiac echocardiography, magnetic resonance imaging and multidetector computed tomography are all used for diagnosis. Coronary angiography is the major diagnostic tool. It can demonstrate the size, anatomy, number, origination and termination site of the fistula ${ }^{6-9}$. Treatment includes medical therapy, transcatheter closure of the fistula or surgical ligation of the fistula. However, these treatments should be tailored according to the size and location of the fistula, and the patient's age and clinical presentation ${ }^{6-10}$.

Coronary AV fistulas originate mostly from the RCA and the left anterior descending artery and have proximal involvement. Clinically, about half of all patients with coronary fistulas are asymptomatic. The management strategy of patients with coronary fistulas depends on the size of the fistula, presence of symptoms, the anatomy of the fistula, the patient's age and whether the patient has other associated cardiovascular disorders. There appears to be a good consensus that all symptomatic patients should undergo closure of medium or large coronary AV fistu$\operatorname{las}^{6-10}$. Because transcatheter closure of coronary AV fistulas is associated with a much shorter recovery time and avoids a scar, it is considered to be the procedure of choice when fistula closure is indicated. Catheter closure can be performed with a variety of techniques, including detachable balloons, stainless steel coils, detached controlled-release coils, controlled-release patent ductus arteriosus coils, patent ductus arteriosus plugs, GianturcoGrifka vascular occlusion device (Cook Medical, Bloomington, IN, USA), regular and covered stents ${ }^{9}$. Surgical ligation should be reserved for patients who have a complex and distally located fistula, or have adjacent vessels at risk. In addition, surgical ligation may be preferred when correction of other congenital defects or coronary artery bypass grafting is required ${ }^{6-9}$.

Given the size and anatomic characteristics of the coronary fistula in this patient, several percutaneous techniques could be used 
including coil embolisation with stainless steel coils, or detachable controlled released coils ${ }^{5,11}$, patent ductus arteriosus (PDA) AMPLATZER plug devices, AMPLATZER ${ }^{\text {TM }}$ Vascular Plugs ${ }^{12-15}$ (St. Jude Medical, St. Paul, MN, USA) and covered stents ${ }^{16,17}$. The atrial branch feeding the fistula is about $2.0-2.5 \mathrm{~mm}$ in diameter and is a non-tortuous vessel. Although coils are used primarily in smaller fistulas, they could be used in this patient. They offer the advantages of smaller sheath and catheter delivery sizes and lower cost. To occlude the distal fistula immediately proximal to the drainage site, coils $20 \%$ to $40 \%$ larger than the maximum diameter of the vessel should be selected. An arteriovenous wire loop to allow transcatheter closure (TCC) from either approach should be created where feasible by first guiding a catheter through the fistula via the aorta, then passing a wire via this catheter into the right heart, where it can be snared and extracted via the femoral vein. The advantage of using detachable coils for TCC of these fistulas is that they are more controllable and therefore much safer when compared to other coils ${ }^{5,11}$. The most important factor in this procedure is to choose the correct coil size, which should exceed the diameter of the fistula by at least $20 \%-40 \%$ in order to prevent coil repositioning or migration. An AMPLATZER Vascular Plug (AVP) is a safe and effective device that has been used for closure of coronary AV fistulas. An AVP, an AVP II and a PDA occluder plug (St. Jude Medical) are devices that should be used for large fistulas, particularly when the orifice is in close proximity to the ostium of the coronary artery ${ }^{12-16}$. Because of the stiffness of its delivery cable, the tip of the guiding catheter for delivering the vascular plug should be placed around 0.5 to $1 \mathrm{~cm}$ from the orifice at the proximal portion of the fistula. The AVP II is a modification of the original PDA plug: it contains three segments instead of only one and provides better immediate occlusion rates in high flow situations. A covered stent (GRAFTMASTER ${ }^{\circledR}$; Abbott Vascular) can be deployed in the RCA and exclude/occlude the coronary fistula. Covered stents, also known as stent grafts, endoluminal grafts or endografts are originally intended for the endovascular repair of aortic or peripheral vascular lesions, including aneurysms, stenoses, dissections and fistulas. There is an array of stent grafts in various sizes and configurations. A stent graft can either be self-expanding or balloon-expandable ${ }^{17,18}$. If this procedure is performed, then optimal geometry expansion of the stent should be guided by either IVUS or OCT, given that the patient is not a candidate for prolonged DAPT.

Related procedural complications include transient ischaemic changes, device embolisation, fistula dissection, transient T-wave changes, transient bundle branch block, myocardial infarction, transient atrial arrhythmia, and death. These complications are rare, except for inadvertent device migration, which can occur as a result of high flow in a large fistula or an undersized device ${ }^{6-9}$. Notably, devices can be retrieved with snares if they migrate 9 . Given the high risk for recurrent stent thrombosis (STEMI presentation, previous stent thrombosis) and contraindication for prolonged DAPT (previous intracerebral bleeding on clopidogrel and aspirin), serious consideration should be given to cardiac surgery including RCA coronary artery bypass grafting and surgical ligation of the RCA to PA AV fistula as a preferred form of therapy ${ }^{6,8}$.

In summary, percutaneous closure of coronary arterial fistula has emerged as a successful therapeutic strategy. The safe and effective results of transcatheter closure support the current convention of elective closure of a clinically significant fistula. The optimal approach depends on the anatomy of the fistula, presence or absence of associated defects, and experience of the interventional cardiologists and surgeons. Coils are primarily used in small to medium-sized fistulae, whereas the AMPLATZER devices and covered stents are used more frequently to occlude larger fistulas. Given the variability of anatomy seen in coronary AV fistulas, the need to apply different techniques for device delivery, as well as the ability to manage various complications, suggests that no single transcatheter method is likely to be successful in all cases, and flexibility in the interventional approach is important.

\section{Conflict of interest statement}

The author has no conflicts of interest to declare. 


\section{How did I treat? ACTUAL TREATMENT AND MANAGEMENT OF THE CASE}

We felt that there was a significant possibility of coronary steal from the coronary artery to the pulmonary artery fistula contributing to the in-stent thrombosis of the recently placed large $5.0 \times 28 \mathrm{~mm}$ bare metal stent, given the proximity of the fistula to the site of recurrent occlusion. Secondary to his history of recurrent intracranial bleeding, it was also felt that minimisation of anticoagulant and obligatory dual antiplatelet therapy would be essential. Due to his frontal lobe syndrome-related behavioural issues and requirement for deep sedation during each procedure, we opted to complete all required interventions in a single session versus staging the interventions. Following re-establishment of TIMI 3 flow, a decision was taken to perform coil embolisation of the fistula, as opposed to covered stenting of the native vessel, to minimise the patient's need for DAPT.

Unfractionated heparin was used for anticoagulation. The RCA was engaged with a 7 Fr Amplatz Right (AR)-1 guide. The lesion in the native RCA was crossed with a 0.014 " Runthrough ${ }^{\circledR}$ wire (Terumo Interventional Systems, Somerset, NJ, USA). Aspiration thrombectomy was performed with a 7 Fr Export ${ }^{\circledR}$ catheter

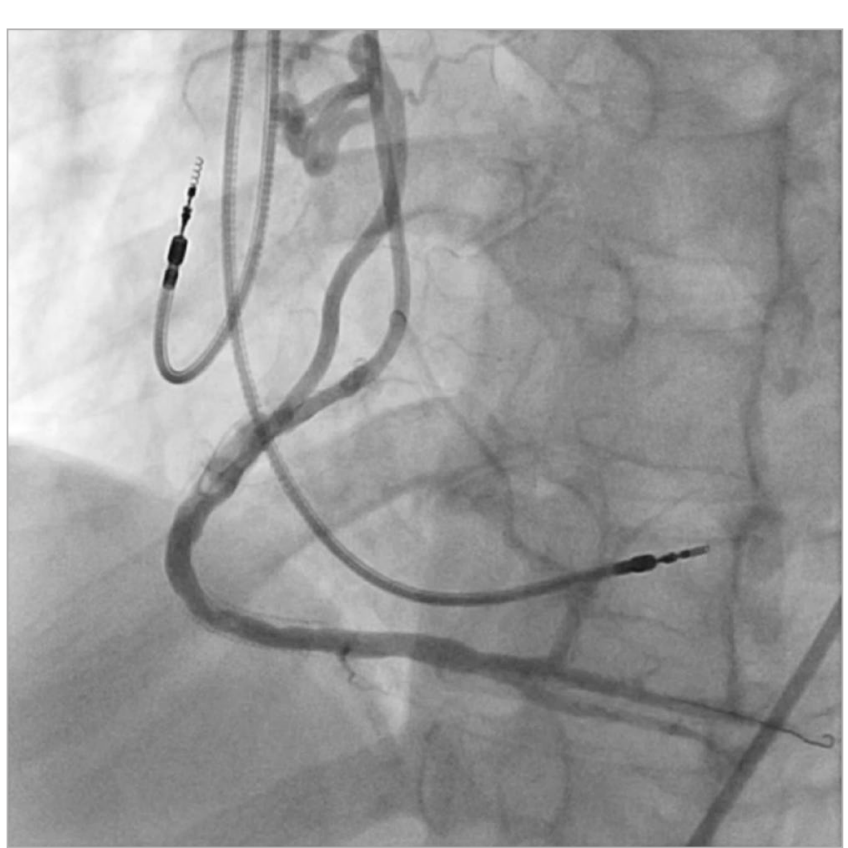

Figure 4. Coronary angiogram showing restoration of TIMI 3 flow in the RCA post balloon angioplasty. Minimal luminal irregularities in the stented portion are visible.
(Medtronic Vascular, Santa Clara, CA, USA), with moderate thrombus burden yield. The lesion was dilated with a $3.0 \times 20 \mathrm{~mm}$ TREK PTCA balloon (Abbott Vascular) to 17 atm for 10 seconds, reestablishing TIMI 3 flow (Figure 4). The fistula was wired with the 0.014" Runthrough wire, pre-loaded on a 2.5 Fr Renegade ${ }^{\mathrm{TM}}$ microcatheter (Boston Scientific, Marlborough, MA, USA), after which the Renegade microcatheter was advanced into the fistula. Five $4 \times 4 \mathrm{~mm}$ Complex Helical- 18 coils and a $3 \times 6 \mathrm{~mm}$ Interlock coil (Boston Scientific) were deployed in the fistula to occlude it (Figure 5).

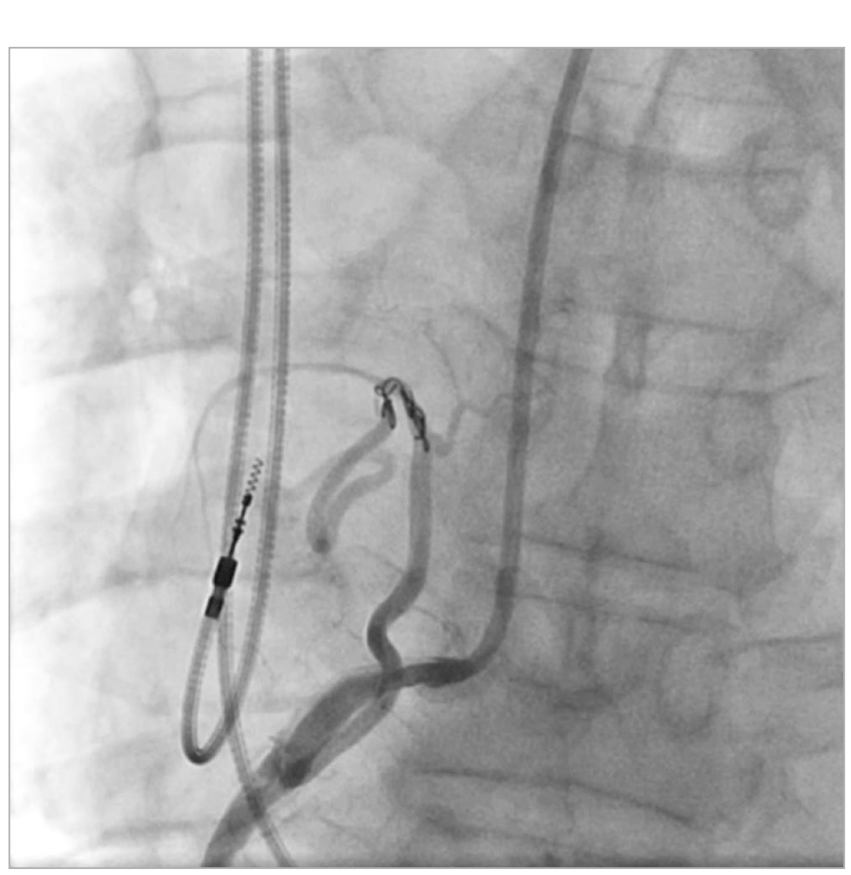

Figure 5. Complex helical coil deployed to occlude the fistula.

The RCA was then re-wired with the Runthrough wire and postdilatation angioplasty was performed with a $4.0 \times 12 \mathrm{~mm}_{\text {Sprinter }}{ }^{\mathbb{B}}$ balloon (Medtronic Vascular) at high pressure. Final results showed occlusion of the fistula and re-establishment of TIMI 3 flow with mild, residual $10 \%$ stenosis (Figure 6). A combination of aspirin and clopidogrel was used for periprocedural antiplatelet therapy for two weeks, after which the patient was switched to aspirin alone. The remainder of his hospital course was uneventful and he remained well at three-month follow-up. 


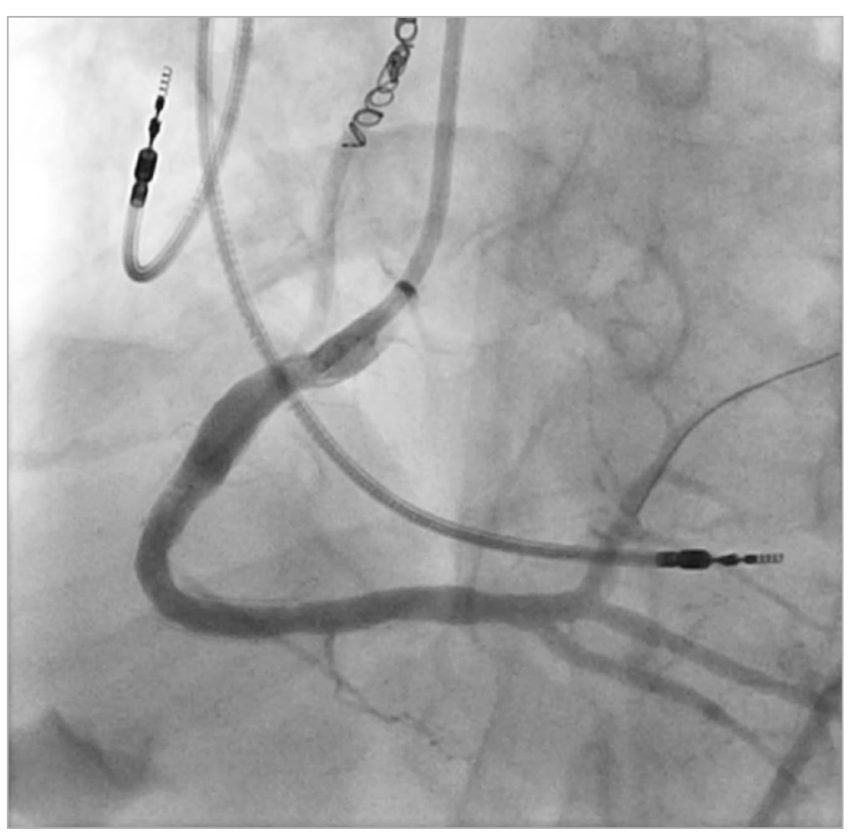

Figure 6. Post-intervention angiogram of the RCA showing the final angiographic result.

\section{Discussion}

Coronary artery fistulas are uncommon congenital anomalies and are found in up to $0.9 \%$ of coronary angiograms ${ }^{19}$. They are occasionally iatrogenic, formed after cardiac surgery or transcatheter interventions ${ }^{20}$. Associations with certain inflammatory diseases such as Takayasu arteritis have also been reported ${ }^{21}$. Among coronary fistulas, 55\% appear to originate from the RCA, 35\% from the left coronary artery and $10 \%$ from both ${ }^{22}$. Common drainage sites include right ventricular structures such as the pulmonary trunk and the right ventricle. Most coronary fistulas are asymptomatic and are incidentally found on coronary angiography. The clinical presentation is dependent on the size of the fistula, shunt volume through the fistula and the area of drainage. Symptomatology varies from anginal chest pain to heart failure and pulmonary hypertension. Based on the clinical presentation and the course of anomalies, a clinical angiographic risk scoring system has been proposed ${ }^{23}$. Associated complications have been described, including bacterial endocarditis, fistula rupture (when aneurysmal), congestive heart failure (when draining into the right ventricle), pulmonary hypertension (when draining into the pulmonary artery) and myocardial ischaemia. Ischaemia, when present, is due to coronary steal phenomenon and reduction of distal coronary flow ${ }^{24}$. Our patient had repeated thrombosis of the mid RCA, probably secondary to the steal from the RCA into the right pulmonary artery. Despite the presence of this fistula, pulmonary hypertension was not present in our patient.

Closure of fistula is the optimal treatment in symptomatic patients. Various methods for closure have been described, including invasive surgical ligation, percutaneous transcatheter coil embolisation, percutaneous implantation of covered stents and percutaneous occluder systems ${ }^{25,26}$. Coil embolisation is generally considered safe, if used in appropriate patients ${ }^{27}$. The coils can be spring coils with Dacron fibres for achieving thrombosis or detachable coils (with interlocking detachable systems). Technical issues related to coiling have occasionally been reported ${ }^{27}$. The detachable coils are retrievable prior to final deployment and can help to avoid inadvertent embolisation ${ }^{28}$. Complications during coiling include rupture of the vessel, coil migration, entrapment of guidewire and death ${ }^{28}$. In patients with complex or multiple fistulas, vascular plugs can be used. These are expandable cylindrical devices that can be delivered through coronary guide catheters. They are generally more expensive compared to coils ${ }^{29}$. In patients with rupture of a fistula, surgical intervention or stent graft implantation is advised ${ }^{1}$.

\section{Conflict of interest statement}

The authors have no conflicts of interest to declare.

\section{References}

1. Wejner-Mik P, Lipiec P, Peruga JZ, Jaszewski R, Pawłowski W, Kasprzak J. Optimal treatment of coronary-to-pulmonary artery fistula: surgery, coil or stent graft? Postepy Kardiol Interwencyjnej. 2013;9:282-5.

2. Palloshi A, Aprigliano G. Myocardial ischemia due to a large coronary-pulmonary fistula with plexus-like morphology. J Cardiovasc Med (Hagerstown). 2008;9:1163-5.

3. Kiuchi K, Nejima J, Kikuchi A, Takayama M, Takano T, Hayakawa H. Left coronary artery-left ventricular fistula with acute myocardial infarction, representing the coronary steal phenomenon: a case report. J Cardiol. 1999;34:279-84.

4. Smettei OA, Abazid RM. A rare case of coronary artery fistula presented with acute myocardial infarction. Avicenna J Med. 2015;5:49-51.

5. Latson LA. Coronary artery fistulas: how to manage them. Catheter Cardiovasc Interv. 2007;70:110-6.

6. Liberthson RR, Sagar K, Berkoben JP, Weintraub RM, Levine FH. Congenital coronary arteriovenous fistula. Report of 13 patients, review of the literature and delineation of management. Circulation. 1979;59:849-54

7. Harris WO, Andrews JC, Nichols DA, Holmes DR Jr. Percutaneous transcatheter embolization of coronary arteriovenous fistulas. Mayo Clin Proc. 1996;71:37-42.

8. Effler DB, Sheldon WC, Turner JJ, Groves LK. Coronary arteriovenous fistulas: diagnosis and surgical management; report of fifteen cases. Surgery. 1967;61:41-50.

9. Armsby LR, Keane JF, Sherwood MC, Forbess JM, Perry SB, Lock JE. Management of coronary artery fistulae. Patient selection and results of transcatheter closure. J Am Coll Cardiol. 2002; 39:1026-32.

10. Valente AM, Lock JE, Gauvreau K, Rodriguez-Huertas E, Joyce C, Armsby L, Bacha EA, Landzberg MJ. Predictors of longterm adverse outcomes in patients with congenital coronary artery fistulae. Circ Cardiovasc Interv. 2010;3:134-9. 
11. Munawar M, Siswanto BB, Harimurti GM, Nguyen TN. Transcatheter closure of coronary artery fistulae using Guglielmi detachable coil. J Geriatr Cardiol. 2012;9:11-6.

12. Weinberg N, French WJ, Shavelle DM. Use of the Amplatzer Vascular Plug for treatment of coronary steal. Int J Cardiol. 2008;124:109-11.

13. Gamboa R, Mollon FP, Rios Mendez RE, Gutierrez DF. Closure of a Coronary Artery Fistula with an Amplatzer Vascular Plug in a Pediatric Patient. Rev Argent Cardiol. 2008;76:233-5.

14. Hill SL, Hijazi ZM, Hellenbrand WE, Cheatham JP. Evaluation of the AMPLATZER vascular plug for embolization of peripheral vascular malformations associated with congenital heart disease. Catheter Cardiovasc Interv. 2006;67:113-9.

15. Fischer G, Apostolopoulou SC, Rammos S, Kiaffas M, Kramer HH. Transcatheter closure of coronary arterial fistulas using the new Amplatzer vascular plug. Cardiol Young. 2007; 17:283-7.

16. Wang SS, Zhang ZW, Qian MY, Zhuang J, Zeng GH. Transcatheter closure of coronary arterial fistula in children and adolescents. Pediatr Int. 2014;56:173-9.

17. Roongsritong C, Laothavorn P, Sa-nguanwong S. Stent grafting for coronary arteriovenous fistula with adjacent atherosclerotic plaque in a patient with myocardial infarction. $J$ Invasive Cardiol. 2000;12:283-5.

18. Jamshidi P, Mahmoody K, Erne P. Covered stents: a review. Int J Cardiol. 2008;130;310-8.

19. Angelini P. Questions on coronary fistulae and microfistulae. Tex Heart Inst J. 2005;32:53-5.

20. Lipiec P, Peruga JZ, Krzeminska-Pakula M, Forys J, Drozdz J, Kasprzak JD. Right coronary artery-to-right ventricle fistula complicating percutaneous transluminal angioplasty: case report and review of the literature. J Am Soc Echocardiogr. 2004;17:280-3.
21. Ercan E, Tengiz I, Yakut N, Gurbuz A, Bozdemir H, Bozdemir G. Takayasu's arteritis with multiple fistulas from three coronary arteries to lung paranchima. Int J Cardiol. 2003; $88: 319-20$.

22. Brussee H, Gasser R. Images in clinical medicine. Fistula connecting the left main coronary artery with the right atrium in a marathon runner. $N$ Engl J Med. 2002;346:904.

23. Rigatelli G, Rigatelli A, Cominato S, Panin S, Nghia NT, Faggian G. A clinical-angiographic risk scoring system for coronary artery anomalies. Asian Cardiovasc Thorac Ann. 2012; 20:299-303.

24. Vijayvergiya R, Bhadauria PS, Jeevan H, Mittal BR, Grover A. Myocardial ischemia secondary to dual coronary artery fistulas draining into main pulmonary artery. Int J Cardiol. 2010; 140:e30-3.

25. Androulakis A, Chrysohoou C, Barbetseas J, Brili S, Kakavas A, Maragiannis D, Kallikazaros I, Stefanadis C. Arteriovenous connection between the aorta and the coronary sinus through a giant fistulous right coronary artery. Hellenic J Cardiol. 2008;49:48-51.

26. Rigatelli G, Cardaioli P. Endovascular therapy for congenital coronary artery anomalies in adults. J Cardiovasc Med (Hagerstown). 2008;9:113-21.

27. Perry SB, Rome J, Keane JF, Baim DS, Lock JE. Transcatheter closure of coronary artery fistulas. J Am Coll Cardiol. 1992;20:205-9.

28. Okubo M, Nykanen D, Benson LN. Outcomes of transcatheter embolization in the treatment of coronary artery fistulas. Catheter Cardiovasc Interv. 2001;52:510-7.

29. MacDonald ST, Carminati M, Butera G. Initial experience with the Amplatzer Vascular Plug IV in congenital heart disease: coronary artery fistula and aortopulmonary collateral artery embolization. J Invasive Cardiol. 2011;23:120-4. 